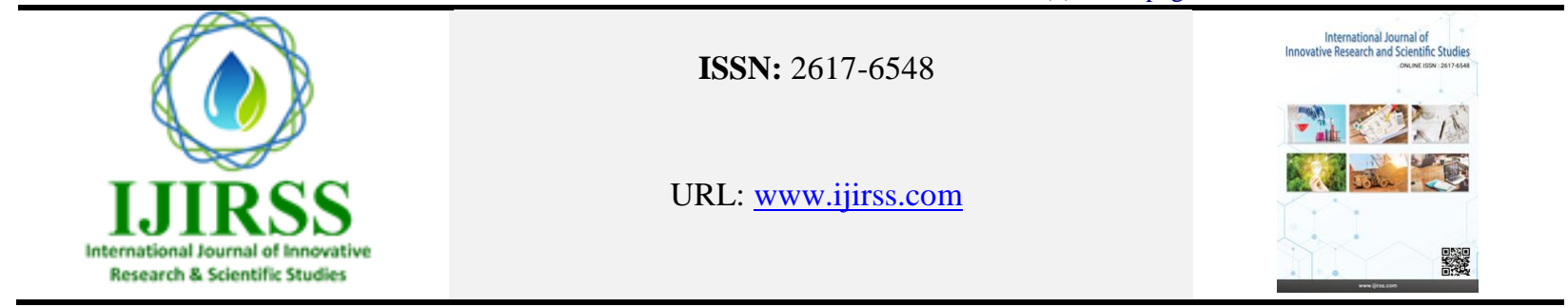

\title{
Comparing the Effectiveness of Conventional and Kano Model Questionnaire for Gathering Requirement of Online Bus Reservation System
}

\author{
Shahwali Shahidi \\ Information System (IS) Department, Faculty of Computer Science, Shahid Prof. Rabbani Education University, Kabul, Afghanistan \\ (Email: shahwali.shahidi@gmail.com)
}

\begin{abstract}
Software development is the activity of creating a software system that when used, solves some unsolved problem. It consists many knowledge intensive processes, among which requirement elicitation process is perhaps the most critical for the success of the software system. The success or failure of the system is related to the quality of the elicitation process and to the method used for gathering user needs. This study examines combined approaches to identify and classify the requirements and investigates the importance of customer satisfaction in requirement elicitation for online bus reservation system. The context of this work is University Malaysia Pahang (UMP). The target audiences are public who uses bus services. A total 63 out of 70 questionnaire are answered by the people. To do this, the design of two types of questionnaires: conventional and Kano questionnaire is done and implemented to identify the correct requirements for the selected system and then to compare the effectiveness of these two approaches. This study found that, both conventional method and Kano model are suitable to find and classify the requirements, but for deeper understanding of requirements which have the greatest influence on the customer's satisfaction, Kano model is more effective, because Kano's method provides valuable help when trade-off is needed for designing the product development.
\end{abstract}

Keywords: Requirement elicitation, Kano model, customer satisfaction.

DOI: 10.53894 /ijirss.v3i1.30

Funding: This study received no specific financial support.

History: Received: 30 December 2019/Revised: 19 February 2020/Accepted: 6 March 2020/Published: 17 March 2020

Licensed: This work is licensed under a Creative Commons Attribution 4.0 License (cc) EY

Competing Interests: The author declares that there are no conflicts of interests regarding the publication of this paper.

Transparency: The author confirms that the manuscript is an honest, accurate, and transparent account of the study was reported; that no vital features of the study have been omitted; and that any discrepancies from the study as planned have been explained.

Ethical: This study follows all ethical practices during writing.

\section{Introduction}

The activity of making software system that when used to solve unsolved problem is called software development [1]. In software development life cycle, specifying the correct requirement for software is one of the problematic issues that play an important role in optimizing the quality of software system [2]. Software development process consists of a series of activities, among these activities requirements elicitation is the most important for the success of the software system.

Elicitation of requirement is a process in which a developer defines the needs and problems of the customer. So, software developer can build a system that in reality fixes the problems of costumer and address their needs [2]. Elicitation of requirement is the process of seeking, uncovering, acquiring, and elaborating requirement for a computer system. This process is not just capturing or collecting requirement, whereas, it is a complex process consisting various activities with different type of accessible technique, approaches, and tools for accomplishing them. Elicitation of requirement is 
concerned with understanding and learning the needs of users and project sponsors with the final objective of communicating these needs to the developer of the system. A considerable part of elicitation is devoted to uncovering, extracting, and surfacing the needs of the potential stakeholders [3]. If elicitation of requirement is not executed correctly and completely, this almost guarantee the final product is a complete failure. Finally, requirements elicitation is the main point of the requirement engineering (RE) process. It's not just the 'collection' of the software requirements, it is the 'discovery' of these requirements. It's an 'extraction' not a 'gathering' process because the requirements are still 'raw' not 'ripe' [4]. As mentioned earlier, finding the correct requirement for a system is very important and it needs to select the appropriate technique.

The initial level of creating software system is the elicitation of requirements. So, errors in this phase of the development are, overall, the most critical in software development, and the most difficult to repair [5]. When gathering user requirements, developers often face different problems such as: Understanding requirements which is a complex issue because it includes natural language to interact with the end-users, and end users may provide imperfect and unclear needs. Everyone knows the difficulty of natural language, but using more formal annotations at the beginning of the phase is a precarious selection that can make requirements inconceivable to understand for users and customers. In addition, analyst do not commonly have good writing skills, and sometimes semantically correct requirements, expressed in natural language are not understood because of the way they are written. Also, requirements are unstable in nature [2]. The may change over the period of time either because of changing needs of users or because of changing perceptions by the stakeholders [5]. If the system requirements are ill-defined, then, essential design information will be left out and instead, inessential design information may be given [5]. So, developers need to select the appropriate method to gather the correct requirements.

Therefore, this article trade-off the efficiency of Kano and conventional questionnaire to find which one is better to elicit the correct requirement and satisfied the customer. In other word, this paper will discuss about design and implementation of questionnaire in order to elicit and shows the customer satisfaction of online bus reservation system. Thus, the objectives of the study were:

- To understand the role and importance of questionnaire technique in eliciting user requirements

- To understanding the characteristics of online bus reservation system that are most important to the customer.

- To find similarity or dissimilarity between conventional and kano model questionnaire.

\section{Literature Review}

To be able to 'elicit' requirements, we need requirements elicitation techniques and to 'elicit' quality requirements, we need a requirements elicitation process. In software engineering, a requirement is an explanation of what a system should do, and the process of collecting and determining as well as extracting and exposing software requirement is called software requirement elicitation. Generally elicitation of requirement is performed by using elicitation technique. There are many techniques available that are widely used for elicitation of requirement. This all technique has the same aim to help analysts in understanding needs. Although, some of the analysts believe that just one technique is suitable to all cases. However, Asim and Sahar [6] believes one technique is not applicable to all situations. This paper discuses a combination of conventional and Kano model to elicit and trade-off the requirement.

\subsection{Questionnaire}

Questionnaire is a popular method, especially in case of big enquiries. It is being acceptable by private individuals, researcher workers, private and public organization and even by governments. In this approaches, a list of questions is distributed to a sample population and their responses are gathered [7, 8]. This technique is also known as 'surveys', questionnaire are used to elicit information from large population. They consist of a written set of questions that resemble a plan for a 'structured' interview. The answers are usually in a 'multiple choice format' so as to aid in analysis [1].

\subsection{Kano Model}

A Kano diagram customer satisfaction is a way of understanding the characteristics of a new product that are most important to the customer. As the Figure 1 shows the model involves two dimensions:

i. Achievement (the horizontal axis) which runs from the product dysfunctional to the product fully functional.

ii. Satisfaction (the vertical axis) that goes from total customer's dissatisfaction with the service or product to total customer's satisfaction with the service or product See Figure 1, [9-12].

Many experts insist that customers don't really know what they want; they have to be told. Customers do know what they want but may not be proficient at their needs. By understanding and how to reveal the three types of customer needs that Dr. Noriaki Kano isolated and identified, researchers will be well on their way to know customers' needs as well as, or perhaps better than, they do [9-12]. These three types of requirements are described in this study.

\section{Must-be Requirements}

This is the requirements that customers expected to be the part of the design or product. If these needs are not executed, the customer will be completely dissatisfied. Conversely, as the customer takes these requirements for granted, their fulfillment will not increase his satisfaction. For instance, if a bus have weak breaks, this causes high customer dissatisfaction, however, if a bus having good breaks it does not increase customer satisfaction [9-12]. 


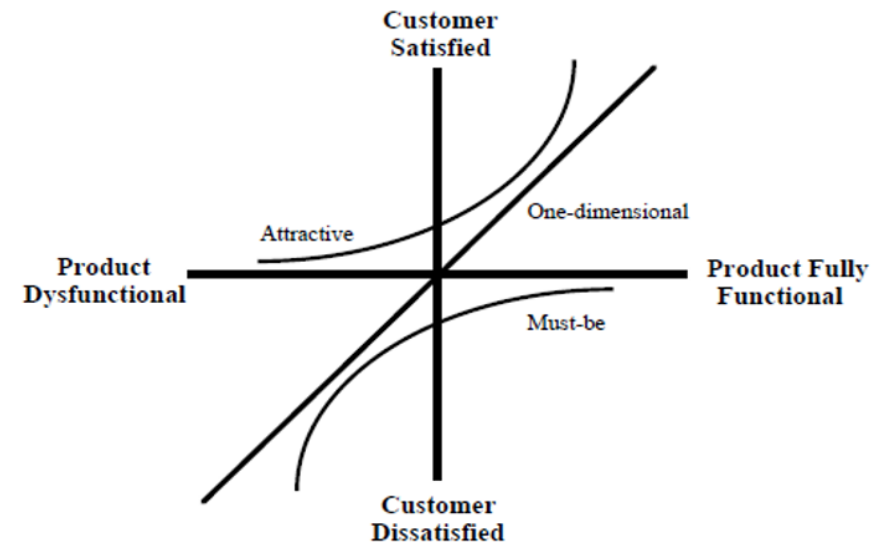

Figure-1.

Kano satisfaction diagram.

One-Dimensional Requirements

These are the requirements that the customer satisfaction level is directly proportional to the level of fulfillment - the higher the level of fulfillment, the higher the customer's satisfaction and vice versa. This category of requirements is usually explicitly demanded by the customers [9-12].

\section{Attractive Requirements}

These are the requirements that customer may not expect them. However, performing these leads to more than proportional satisfaction. On the other hand, if they are not met, there is no dissatisfaction. These expectations are also known as the delighters or exciters because they go well beyond anything the customer might imagine [9-12].

\section{Research Methodology}

The way how to methodically do the research is called research methodology. There are many ways to conduct the research and find the solution for problem that is facing the researcher during the research. In the area of requirements elicitation many methods can be used such as interview, questionnaire, viewpoint, observation, task analysis, domain analysis, group work, brainstorming and so on. University Malaysia Pahang were the research scope of this study. In this study for gathering users need, questionnaires are used; the questionnaire were distributed to the 70 people who are using online bus reservation system application to perform their daily task and also to the customer who uses these existing online ticketing service to perform a bus ticket purchase. But, 63 out of 70 questionnaire are answered by people and 7 questionnaire were missed. For gathering requirements a combination of conventional and Kano questionnaire, and for analyzing the data that are obtained from questionnaire, IBM SPSS software were used.

\section{Results and Discussion}

Doing requirements engineering correctly requires an interdisciplinary approach that considers the needs of multiple stakeholders groups [13]. This study provides an integration of Kano model and conventional questionnaire to investigate the importance of customer satisfaction in requirement elicitation. Kano model is applied to find-out the needs of customer and determine customer satisfaction coefficient that helps the manager to trade-off which is the most important quality for increasing satisfaction. In this study, the Kano model was applied to the online bus reservation system.

Table-1.

Very-important and must-be requirements comparison

\begin{tabular}{|c|c|c|c|c|c|}
\hline \multicolumn{6}{|c|}{ Very-important $\approx$ Must-be } \\
\hline \multirow{2}{*}{ No } & \multirow{2}{*}{ Assessed requirements } & \multicolumn{2}{|l|}{$\begin{array}{l}\text { Conventional } \\
\text { questionnaire }\end{array}$} & \multicolumn{2}{|l|}{$\begin{array}{l}\text { Kano } \\
\text { questionnaire }\end{array}$} \\
\hline & & $\begin{array}{l}\text { Number of } \\
\text { respondents }\end{array}$ & Category & $\begin{array}{l}\text { Number of } \\
\text { respondents }\end{array}$ & Category \\
\hline 1 & Check seat availability & 51 & V-important & 24 & $\mathrm{M}$ \\
\hline 2 & Check bus schedule & 56 & V-important & 21 & $\mathrm{M}$ \\
\hline 3 & See fare list & 38 & V-important & 20 & $\mathrm{M}$ \\
\hline 4 & Cancel booking & 45 & V-important & 19 & $\mathrm{M}$ \\
\hline 5 & Print ticket & 26 & V-important & 20 & M \\
\hline 6 & Display confirmation of reservation & 49 & V-important & 22 & $\mathrm{M}$ \\
\hline 7 & Payment method & 41 & V-important & 24 & $\mathrm{M}$ \\
\hline
\end{tabular}

According to analysis using the data obtained from Kano and conventional questionnaire survey, as seen in the Table 1 and 6 most of the requirement that are "very-important" in the conventional questionnaire are "must-be" requirement in 
the Kano questionnaire, such as: "check seat availability", "check bus schedule", "see fare list", "cancel booking", "print ticket", "display confirmation of reservation", and " payment method". For example, "check bus schedule" with dramatically difference in the number of respondent which is 56 respondents in the conventional and 21 respondents in the Kano questionnaire are selected this product item as "very-important" and "must-be" requirement respectively. While "print ticket" item with slightly difference in the number of respondent ( 26 respondent in conventional and 20 respondent in Kano questionnaire) are selected as very-important in conventional questionnaire and "must-be" in Kano questionnaire. It means that this requirements are very-important, and these are Must-be fulfilled first, otherwise, there would be major dissatisfaction.

Then, the product items that are classified as "important" requirement in conventional questionnaire are classified as "one-dimensional" requirement in the Kano questionnaire. As shown in the Table 2 and 6 "member registration" with 42 respondent in the conventional questionnaire and 22 respondent in the Kano questionnaire are categorized this product item as "important" and "one-dimensional" requirements respectively.

Table-2.

Important and One-dimensional requirements comparison.

\begin{tabular}{|c|c|c|c|c|c|}
\hline \multicolumn{6}{|c|}{ important $\approx$ One-dimensional } \\
\hline \multirow{2}{*}{ No } & \multirow{2}{*}{ Assessed requirements } & \multicolumn{2}{|c|}{ Conventional questionnaire } & \multicolumn{2}{|l|}{$\begin{array}{l}\text { Kano } \\
\text { questionnaire }\end{array}$} \\
\hline & & $\begin{array}{l}\text { Number of } \\
\text { respondents }\end{array}$ & Category & $\begin{array}{l}\text { Number of } \\
\text { respondents }\end{array}$ & Category \\
\hline 1 & Member registration & 42 & important & 22 & $\mathrm{O}$ \\
\hline 2 & Choose number of passenger & 31 & important & 18 & $\mathrm{O}$ \\
\hline 3 & Choose number of children & 35 & important & 20 & $\mathrm{O}$ \\
\hline
\end{tabular}

Moreover, "choose number of passenger" with 31 respondents in conventional requirement classified as "important" requirement, and with 18 respondents in the Kano questionnaire are classified as "one-dimensional" requirement. Lastly, "choose number of children" with 35 respondents in the conventional questionnaire and 20 respondents in the Kano questionnaire is categorized as important and one-dimensional requirements respectively. Thus, this study shows that onedimensional requirements are an important requirement and it should be fulfilled after the must-be requirements. Fulfilling of one-dimensional requirements can largely increase customer satisfaction. Table 1 and 2 show big difference in the result between responses of conventional questionnaire and Kano questionnaire respondents, possible reason for these differences could be:

-Kano questionnaire is complicated.

-Respondent did not know how to answer.

-The number of occurrences for Kano comes after some evaluation.

As shown in the Table 3 and 6 those requirement that are classified as "less-important" requirements in the conventional questionnaire are classified as attractive requirements in the Kano questionnaire. It shows that omission of these requirements does not have any negative effect on the system and do not led the customer to dissatisfied, but presence of this requirement make the customer very satisfied.

Table-3.

\begin{tabular}{|c|c|c|c|c|c|}
\hline \multicolumn{6}{|c|}{ Less-important $\approx$ Attractive } \\
\hline \multirow{2}{*}{ No } & \multirow{2}{*}{$\begin{array}{l}\text { Assessed } \\
\text { requirements }\end{array}$} & \multicolumn{2}{|l|}{$\begin{array}{l}\text { Conventional } \\
\text { questionnaire }\end{array}$} & \multicolumn{2}{|l|}{$\begin{array}{l}\text { Kano } \\
\text { questionnaire }\end{array}$} \\
\hline & & $\begin{array}{l}\text { Number } \\
\text { respondents }\end{array}$ & Category & $\begin{array}{l}\text { Number } \\
\text { respondents }\end{array}$ & Category \\
\hline 1 & $\begin{array}{l}\text { Select } \\
\text { seat(window/non- } \\
\text { window) }\end{array}$ & 25 & $\begin{array}{l}\text { L- } \\
\text { Important }\end{array}$ & 25 & A \\
\hline 2 & $\begin{array}{l}\text { Select } \\
\text { seat(single/double } \\
\text { seat line) }\end{array}$ & 35 & $\begin{array}{l}\text { L- } \\
\text { important }\end{array}$ & 21 & A \\
\hline 3 & $\begin{array}{lr}\begin{array}{l}\text { Send SMS } \\
\text { change } \\
\text { customer }\end{array} & \text { for } \\
\end{array}$ & 22 & $\begin{array}{l}\text { L- } \\
\text { important }\end{array}$ & 21 & A \\
\hline 4 & $\begin{array}{l}\text { Distinguishing } \\
\text { between } \\
\text { rush/normal time }\end{array}$ & 28 & $\begin{array}{l}\text { L- } \\
\text { important }\end{array}$ & 32 & A \\
\hline
\end{tabular}


This requirements are: "Select seat (window/non-window)", "Select seat (single/double seat line)", "Sending SMS of change for customer", and "Distinguish between rush/normal time". For example, "Select seat (window/non-window) with 25 respondent for both conventional and Kano questionnaire are matched to "less-important" requirement in the conventional questionnaire and "attractive" requirement in the Kano questionnaire. But "Send SMS of change for customer" with slightly difference (22 and 21 respondents for conventional and Kano questionnaire respectively) are classified to "less-important" in the conventional and "attractive" requirement in the Kano questionnaires.

As seen in Table 4, those requirements that are "neutral" in the conventional questionnaire are categorized as Indifferent requirement in the Kano questionnaire. For this kind of requirements the customer is neither satisfied nor dissatisfied if the product or service is dysfunctional or fully functional. These kinds of requirements are: "user polling", "send feedback", and "view and send forum". For instance, "user polling" with 31 respondents in conventional and 25 respondents in Kano questionnaire with moderately difference classified to "neutral" and "indifferent" requirements respectively. While, "send feedback" requirement with slightly difference (32 and 33 respondents for conventional and Kano questionnaire respectively) are classified to "neutral" in conventional and "indifferent" requirements in the Kano questionnaire.

Table-4.

Important and One-dimensional requirements comparison.

\begin{tabular}{|c|c|c|c|c|c|}
\hline \multicolumn{6}{|c|}{ Neutral $\approx$ Indifferent } \\
\hline \multirow{2}{*}{ No } & \multirow{2}{*}{ Assessed requirements } & \multicolumn{2}{|c|}{ Conventional questionnaire } & \multicolumn{2}{|l|}{$\begin{array}{l}\text { Kano } \\
\text { questionnaire } \\
\end{array}$} \\
\hline & & $\begin{array}{l}\text { Number of } \\
\text { Respondents }\end{array}$ & Category & $\begin{array}{l}\text { Number of } \\
\text { respondents }\end{array}$ & Category \\
\hline 1 & User polling & 31 & Neutral & 25 & Indifferent \\
\hline 2 & Send feedback & 32 & Neutral & 33 & Indifferent \\
\hline 3 & View and send forum & 28 & Neutral & 35 & Indifferent \\
\hline
\end{tabular}

Table-5.

Exception case requirement.

\begin{tabular}{|c|c|c|c|c|c|}
\hline \multicolumn{6}{|c|}{ Exception case } \\
\hline \multirow{2}{*}{ No } & \multirow{2}{*}{ Assessed requirements } & \multicolumn{2}{|c|}{ Conventional questionnaire } & \multicolumn{2}{|l|}{$\begin{array}{l}\text { Kano } \\
\text { questionnaire }\end{array}$} \\
\hline & & $\begin{array}{l}\text { Number of } \\
\text { respondents }\end{array}$ & Category & $\begin{array}{l}\text { Number of } \\
\text { respondents }\end{array}$ & Category \\
\hline 1 & Member login & 34 & V-important & 23 & $\mathrm{O}$ \\
\hline 2 & View company's bus information & 37 & Important & 21 & $\mathrm{M}$ \\
\hline
\end{tabular}

Table-6.

Comparison of Kano and conventional questionnaire.

\begin{tabular}{l|l|l|l}
\hline Question \# & Assessed characteristics & Kano questionnaire & $\begin{array}{l}\text { Conventional } \\
\text { questionnaire }\end{array}$ \\
\hline 1 & Member Registration & O & 4 (Important) \\
\hline 2 & Member Login & O & 5 (Very-important) \\
\hline 3 & User Polling & I & 3 (Neutral) \\
\hline 4 & View Company's Bus Information & M & (Important) \\
\hline 5 & Check Seat Availability & M & 5 (Very-important) \\
\hline 6 & Check Bus Scheduling & M & (Very-important) \\
\hline 7 & See Fare List & A & 5 (Very-important) \\
\hline 8 & Select Seat (Window / Non-window ) & A & 2 (Les-important) \\
\hline 9 & Select Seat (Single / Double seat line ) & M & 2 (Les-important) \\
\hline 10 & Cancel Booking & M & 5 (Very-important) \\
\hline 12 & Print Ticket & I & 5 (Very-important) \\
\hline 13 & Send Feedback & I & 3 (Neutral) \\
\hline 14 & View and Send Forum & O & 3 (Neutral) \\
\hline 15 & Choose Number of Passenger & O & 4 (Important) \\
\hline 16 & Choose Number of Children & A & 4 (Important) \\
\hline 17 & Sending SMS of change for customer. & A & 2 (Les-important) \\
\hline 18 & Distinguishes between "Rush/Normal time" & M & 2 (Les-important) \\
\hline 19 & Display confirmation of reservation & M & 5 (Very-important) \\
\hline
\end{tabular}

As seen in Table 5, in some exception case as it is clear that customer in different segment have different product expectation, like: "member login" in Kano questionnaire is categorized as "one-dimensional" requirements, it should be 
categorized as "important" requirement in conventional questionnaire, but it is categorized as "very-important" requirements or vice versa.

In addition, "view company's bus information" is classified as important requirement in the conventional question, it should be classified to one-dimensional requirement in the Kano questionnaire, but it is classified as Must-be requirement in Kano questionnaire or vice versa.

\section{Conclusion}

Based on the result and discussion from this study, the conventional questionnaire identified the correct requirements for aforesaid system, and also rated the importance of each requirements. On the other hand Analysis of the Kano questionnaire results in classification of the product characteristics into the four types of requirements defined above (A, $\mathrm{O}$, $\mathrm{M}$, and I). Since respondents may not rate all attributes included in the questionnaire in these categories, other classifications are also possible: questionable $(\mathrm{Q})$, and reverse $(\mathrm{R})$.

Furthermore, this model can distinguish between three types of product requirement $(\mathrm{A}, \mathrm{O}$, and $\mathrm{M})$ which influence customer satisfaction in different ways when met. In addition, for deeper understanding of customer requirements, this research has compared the conventional questionnaire and Kano questionnaire analysis. And found that most of product requirements that categorized as "Must-be" requirement in the Kano questionnaire are "Very-important" category in the conventional questionnaire, one-dimensional" requirements in the Kano questionnaire are classified as "important" requirement in the conventional questionnaire, and "attractive" requirements in Kano questionnaire are classified as "lessimportant" in conventional requirements, and finally, the "indifferent" requirements in Kano questionnaire are classified as "neutral" requirement in conventional questionnaire.

\section{References}

[1] A. M. Hickey and A. M. Daivs, "Requirements elicitation and elicitation technique selection: A model for two knowledgeintensive software development processes," in Proceedings of the 36th Annual Hawaii International Conference on System Sciences, 2003.

[2] S. Tiwari, S. S. Rathore, and A. K. Gupta, "Selecting requirement elicitation techniques for software projects," presented at the CSI Sixth International Conference on Software Engineering (CONSEG), IEEE, 2012.

[3] C. Wohlin, Engineering and managing software requirements: Springer Science \& Business Media, 2005.

[4] I. Bray, An Introduction to requirements engineering. Reading, MA: Addison-Wesley, 2002.

[5] P. Rajagopal, R. Lee, T. Ahlswede, C. C. Chiang, and D. Karolak, "New approach for software requirements elicitation, In software engineering, artificial intelligence, networking and parallel/distributed computing," presented at the ACIS International Workshop on Self-Assembling Wireless Networks. SNPD/SAWN, Sixth International Conference on IEEE, (2005), 2005

[6] M. Asim and F. Sahar, "Advance topics in software engineering topic: Requirement elicitation techniques case study: Online vehicle trading," Bleking Institut of Technology, 2009.

[7] D. Jain, Software engineering principles and practices. India: Engineering and R\&D Services, HCL Technologies Limited, 2009.

[8] C. R. Kothari, Research methodology: Methods and techniques: New Age International, 2004.

[9] S. Lin and D. Niu, "Empirical study on electric power customer satisfaction based on Kano model," presented at the Services Science, Management and Engineering, 2009. SSME'09. IITA International Conference, IEEE, 2009.

[10] E. Sauerwein, F. Bailom, K. Matzler, and H. H. Hinterhuber, "The Kano model: How to delight your customers," in International Working Seminar on Production Economics, 1996, pp. 313-327.

[11] Y. Sireli, P. Kauffmann, and E. Ozan, "Integration of Kano's model into QFD for multiple product design," IEEE Transactions on Engineering Management, vol. 54, pp. 380-390, 2007. Available at: https://doi.org/10.1109/tem.2007.893990.

[12] D. Walden, "Center for quality of management journal," pp. 1-110, 2001.

[13] L. Westfall, "Software requirements engineering: What, why, who, when, and how," Software Quality Professional, vol. 7, p. 17,2005 . 